\title{
Effects of aerial exposure on size of the common barnacle (Semibalanus balanoides), an inhabitant of the intertidal zone in St. Andrews, New Brunswick
}

\begin{abstract}
Katie Bell
This study was conducted at the Huntsman Marine Center and the manuscript was prepared under the supervision of Professor Todd Gillis, Department of Integrative Biology, College of Biological Science.

Survival in the intertidal zone for sessile marine invertebrates means enduring the drastic changes in environmental conditions that comes with tide cycling. An influential repercussion for Semibalanus balanoides, the common barnacle, is changes in food accessibility. As a filter-feeder, this intertidal organism does not obtain the required nutrients for growth when exposed to air and, as a result, experiences a compromised growth rate along with a limited body size. A four-day (August $16^{\text {th }}-19^{\text {th }}, 2009$ ) field-based study was conducted at Indian Point in St. Andrews, New Brunswick to examine how duration of aerial exposure affects rostro-carinal length (body size). Twenty $10 \mathrm{~cm} \times 10 \mathrm{~cm}$ sites were sampled within which the total number of $S$. balanoides individuals was counted and rostro-carinal lengths of 50 individuals were measured. In support of the predicted results, this study shows that aerial exposure limits body size in $S$. balanoides. This negative relationship between duration of aerial exposure and body size is largely correlative, as supported by the $\mathrm{R}=0.9205$ value obtained through application and analysis of the linear regression model. This information of how $S$. balanoides responds to the out of water experience may bring to light the significance of results from lab-based studies regarding environmental conditions that $S$. balanoides can tolerate.
\end{abstract}

\begin{abstract}
A $s$ a result of semidiurnal tide cycling, marine inhabitants of the intertidal zone are periodically exposed to the harsh conditions of the terrestrial world. ${ }^{1,2}$ With the retreat of the tide, previously submerged sites become exposed to greater temperature fluctuations, altered feeding patterns, and the evaporative effects of sunlight. ${ }^{3,4,5}$ Under these stressful conditions, the ability to relocate to more favorable sites confers an advantage to mobile marine life. ${ }^{1,5}$ Absent of this luxury of retreating with the tide into the safety of the sea, sessile intertidal inhabitants are forced to endure the physiological stresses of exposure during low tide.

The study of the survivability of sessile marine life in the intertidal zone strives to achieve an understanding of the processes that drive species distribution and/or ecosystem dynamics. In particular, Semibalanus balanoides, the common barnacle, is an extensively studied species of sessile intertidal marine life; research and observational results provide an array of information about its physiology and ecological role in marine ecosystems across the globe. ${ }^{1,5,6}$ Given current knowledge of the zonation patterns displayed by $S$. balanoides in the intertidal zone, this organism is ideal for studying the influences of aerial exposure on its survivability. ${ }^{1,5}$ Of the factors found to impact the survival of S. balanoides, including competition, predation, desiccation, water current, and location of settlement, food accessibility has been identified as being of paramount importance. ${ }^{6,7,8}$
\end{abstract}

Through an analysis of how the duration of aerial exposure affects body size, this paper provides a field-based examination of the influence of settlement location in the intertidal zone on population and community dynamics of $S$. balanoides. Individuals studied included only those that had settled onto rock substrate during the same year of data collection (anytime between the end of March and early April of 2009).

As a filter feeder, $S$. balanoides must be submerged in order to feed. Since food is a necessity for this species to grow, it is hypothesized that aerial exposure impedes the ability to feed and, as such, limits growth. It is expected that $S$. balanoides on rock substrate found closer to the shore will be smaller than those found further down the intertidal zone, since a location higher up the intertidal zone translates to more time spent out of water during each tidal cycle (one low tide and one high tide) and therefore less time to feed.

\section{MATERIAls ANd Methods}

\section{Establishing Sampling Sites}

This field study was carried out over four days (August $16^{\text {th }}$ $19^{\text {th }}, 2009$ ) at Indian Point of St. Andrews, New Brunswick.

Time of day for sampling was dictated by the semidiurnal tide. Sampling began each day at high tide and 


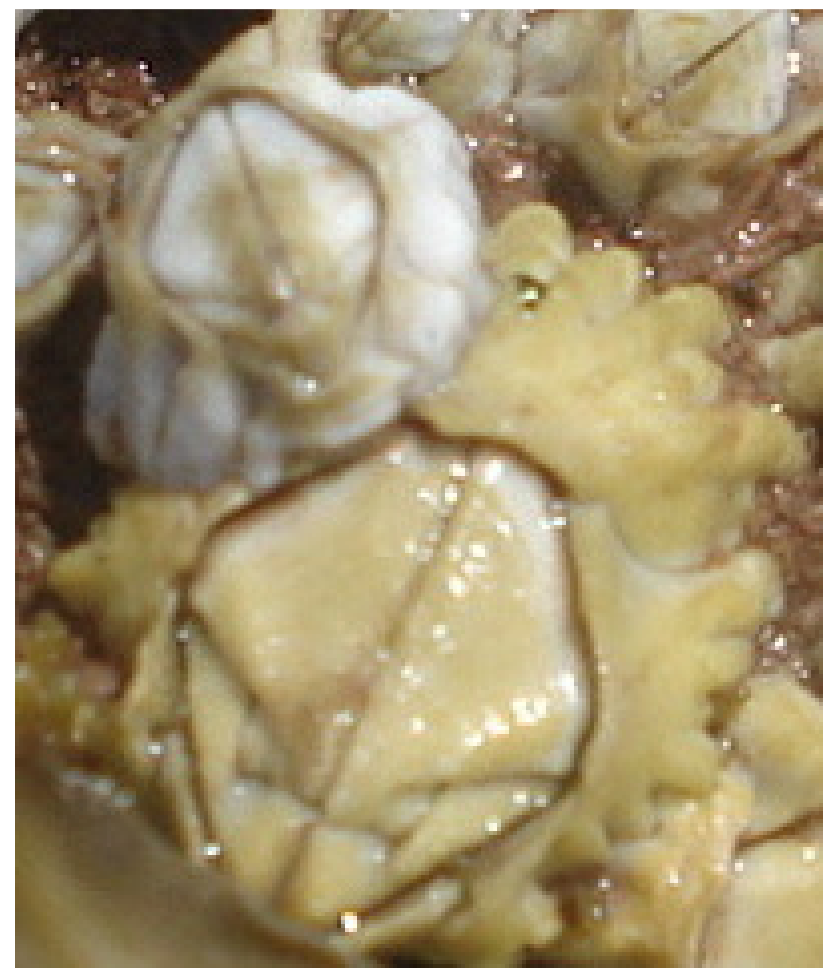

Figure 1: Distinguishing between Semibalanus balanoides that settled in previous years (beige-green-brown colouration) and $S$. balanoides that settled this year (white colouration).

was completed just after low tide. Tide tables were consulted for tide times.

A total of twenty different sites were sampled, with five sites examined each day. Following sampling, all sites were marked using coloured vinyl tape to allow for further documentation of the overall sampling area at the end of the four days.

Sites were established each day by moving down the intertidal zone with the retreating tide. A site was determined fit for sampling according to three criteria: the substrate was rock, the $S$. balanoides inhabitants were positioned with the operculum facing upwards (toward the surface of the water when submerged), and there was an unobstructed passage of water flow (no larger rock or other barriers were close by). By following this protocol, it was assumed that all individuals had the same access to food when submerged. With this assumption, the possible effects of operculum positioning on $S$. balanoides body size were accounted for, and as such, comparisons between sites could be drawn. A previous study determined that $S$. balanoides with an operculum oriented toward the current has an increased feeding opportunity and subsequent enhanced growth, while large barriers limit growth through decreased feeding. ${ }^{8}$

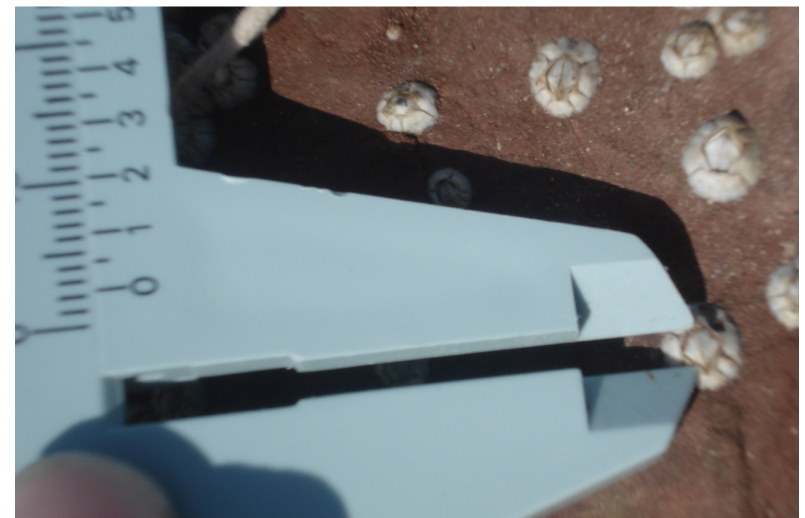

Figure 2: Measuring distance $(\mathrm{mm})$ between rostrum and carina wall plates to determine rostro-carinal length by use of a caliper. Distinguishing between rostrum and carina was not required as the aperture, or point of opening between opercular plates, runs perpendicular, from one plate to the other. Therefore, the aperture was used as the reference for measuring the rostro-carinal length. The rostro-carinal length was used as an indicator of size of each Semibalanus balanoides individual.

\section{Data Collection}

A start site onshore was marked such that it could be visually identified from low tide. This site was used for reference to maintain a fairly straight line while sampling down the intertidal zone.

Rocky substrate occupied by $S$. balanoides, with proper positioning as described earlier, was identified for the location of Site 1, close to shore, while still submerged by the tide. The time of day when barnacles at this location became exposed to air was observed and recorded. A quadrate $(10 \mathrm{~cm} \times 10 \mathrm{~cm})$ was placed randomly on this location to represent Site 1. The total number of $S$. balanoides inhabitants was counted. A pencil was used to mark individuals to avoid inaccuracy from recounting.

To account for different growth rates between differently aged $S$. balanoides, only individuals that had settled this year ('new') were considered in this study. ' $\mathrm{New}$ ' individuals were distinguished from 'old' individuals (those settled in previous years) by identification of differences in shell colouration (Figure 1). Shell colouration is a reliable guide to identify barnacles that had settled during the same year that they are observed as distinct from barnacles that had settled in previous years. ${ }^{9}$

A caliper was used to measure the rostro-carinal length (the distance between the rostrum and carina wall plates) of 50 'new' $S$. balanoides out of all of those that were counted (Figure 2). Although volume is a more accurate measurement of size of the whole animal, the rostro-carinal length is an appropriate measurement because the shape change of $S$. balanoides is insignificant with age. ${ }^{10}$ Furthermore, taking the one rostro-carinal length measurement was more practical given the time constraints 


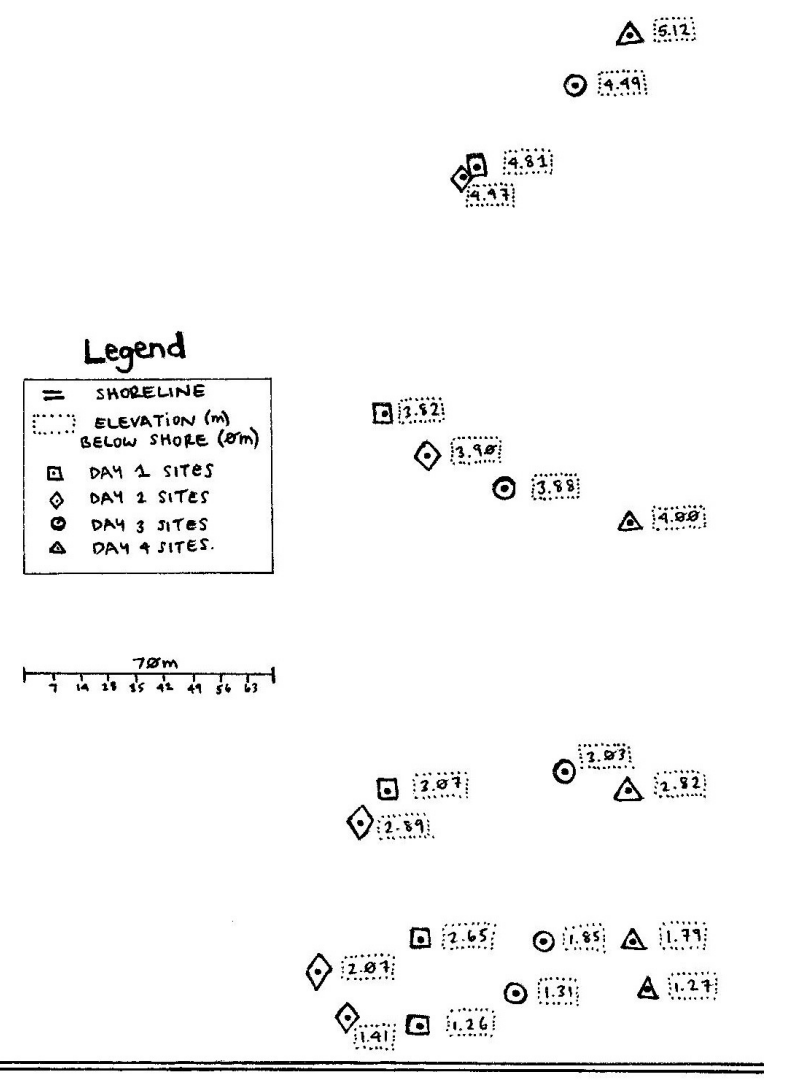

Figure 3: Drawing, to scale, of sampling area layout including the elevations below shoreline (m) and locations of all twenty sites sampled over the four days.

of the field study. A pencil mark was applied to measured individuals to avoid duplication.

A HOBOware data logger was positioned at the site to record the time of day that the sampled $S$. balanoides became submerged.

Sampling at the other four sites (Sites 2, 3, 4, and 5) followed the same procedure implemented at Site 1 . However, due to a deficiency in the number of data loggers available for use, a data logger was not placed at Site 5; instead the time of day that $S$. balanoides became submerged by the incoming tide was observed and recorded.

The above five-site sampling method was repeated three times, once on each of the next three days. All start sites were arranged such that they were positioned within a $75 \mathrm{~m}$ distance, parallel to shore, in order to make the charting of each site's location with respect to the shore easier (Figure 3).

\section{Mapping out the Sample Area}

A theodolite was used to determine the elevation of each site with respect to shore. The theodolite was setup onshore in a central position relative to all start sites. The height of the theodolite was measured from the base of the theodolite (mounted on a stand) to the ground. This value was noted

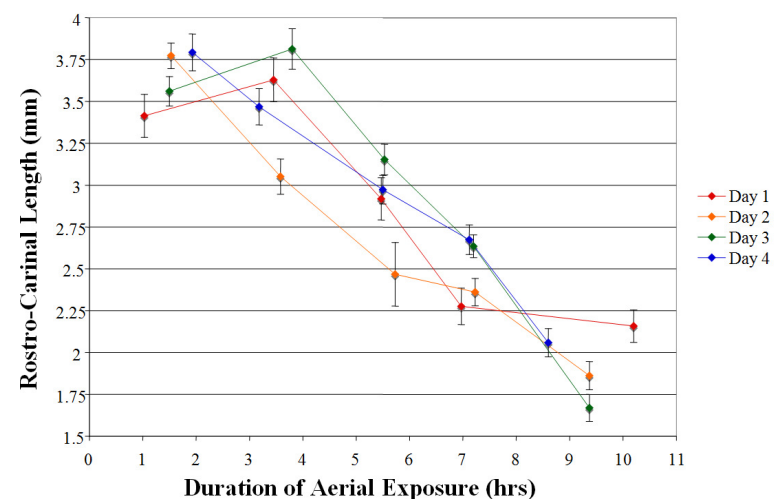

Figure 4: Average rostro-carinal lengths of the common barnacle (Semibalanus balanoides) collected over four sampling days, as a measure of average size at different locations along the intertidal zone. Duration of aerial exposure (hrs) recorded over one tidal cycle (one high tide and one low tide) of the semidiurnal tide. Values are means \pm 1 s.e.m. of fifty rostro-carinal length measurements.

and discounted from elevation readings taken for each site. Elevation (m) below shore was documented as the measurement read on the multi-meter meter stick.

A $60 \mathrm{~m}$ open reel measuring tape was used to map out the location of the sites with respect to one another. Distance between shore and the first site for each day was determined. The distance between sites was measured by moving, parallel to shore, across the sample area beginning at Site 1 and ending at Site 5 .

\section{Determining Duration of Aerial Exposure}

As described above, the time of day when $S$. balanoides became exposed to air was observed and noted prior to sampling at each site.

The data collected by the HOBOware data loggers was graphically analyzed. The time of day when each sampling site became submerged was indicated on the graph by a sudden drop in temperature. The use of this method is based on the understanding that the incoming ocean water $\left(\sim 13^{\circ} \mathrm{C}\right)$ was cooler than the sunny and hot atmosphere $\left(\sim 30^{\circ} \mathrm{C}\right)$ endured by $S$. balanoides when exposed. The duration of aerial exposure (hours) during one tidal cycle was calculated by the difference between the time when $S$. balanoides became exposed and were then submerged.

\section{RESULTS}

A linear regression model was applied to the data presented in Figure 4 of $S$. balanoides average rostro-carinal lengths measured at each site. As shown in Figure 5, the coefficient of determination $\left(\mathrm{R}^{2}\right)$, valued at 0.8474 , and a trend line with the equation $y=-0.2218 x+4.0863$, provides insight into the relationship between the average rostro-carinal length and duration of aerial exposure for $S$. balanoides inhabiting each 


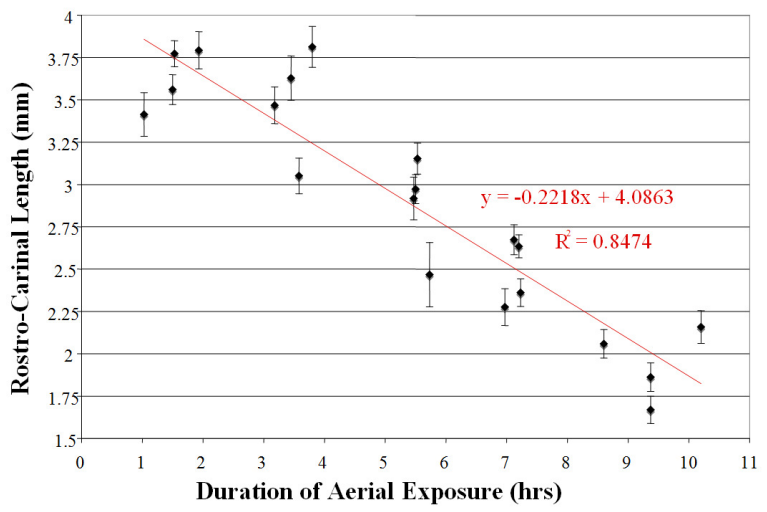

Figure 5: Linear regression applied to average rostrocarinal lengths $(\mathrm{mm})$ of the common barnacle (Semibalanus balanoides) found at different intertidal locations from the four sampling days. Duration of aerial exposure (hr) recorded over one tidal cycle (one high tide and one low tide) of the semidiurnal tide. Values are means $\pm \mathbf{1}$ s.e.m. of fifty rostro-carinal length measurements. Equation of linear regression line and coefficient of determination value $\left(\mathbf{R}^{2}\right)$ expressed on graph.

site. The $\mathrm{R}^{2}$ value indicates that $84.74 \%$ of the variation in size of $S$. balanoides is explained by the variation in time spent by these organisms exposed to air. Furthermore, the equation of the line, specifically the negative slope, makes it evident that with greater duration of aerial exposure $S$. balanoides are smaller on average, having shorter rostrocarinal lengths. The significance of this negative relationship, and whether $S$. balanoides body size is correlated with the time that these barnacles are exposed to air, may be understood through further analysis of the $\mathrm{R}^{2}$ value. Since the measured $S$. balanoides represents a sample of all $S$. balanoides occupying the sampling area at Indian Point, the sample correlation coefficient (R) may be calculated by taking the square-root of the $\mathrm{R}^{2}$ value. Where $\mathrm{R}=1.0$ indicates that variables are perfectly correlated, the calculated $\mathrm{R}$ value is 0.9205 . This value, along with the negative slope of the linear regression line, indicates that the size of $S$. balanoides is highly negatively correlated with duration of aerial exposure.

As displayed in Figure 6, the density (\# of individuals $/ \mathrm{cm}^{2}$ ) of $S$. balanoides inhabitants was graphed with the average rostro-carinal length measurements for each respective site. To gain insight into how these factors are related, a linear regression model was applied to this data. To allow for a more direct examination of how density influences rostro-carinal length, and account for the affects of aerial exposure on rostro-carinal length, similar located sites were grouped together. For respective groupings of sites $1,2,3,4$ and 5 the equations of the lines are $\mathrm{y}=0.0214 \mathrm{x}+1.579, \quad \mathrm{y}=-0.312 \mathrm{x}+3.1715, \mathrm{y}=-0.0249 \mathrm{x}+3.6144$, $\mathrm{y}=-0.0465 \mathrm{x} 4.4688$, and $\mathrm{y}=-0.0096 \mathrm{x}+3.7906$, as displayed in Figure 6. The $\mathrm{R}^{2}$ value for the Site 1 grouping is 0.3834 ,

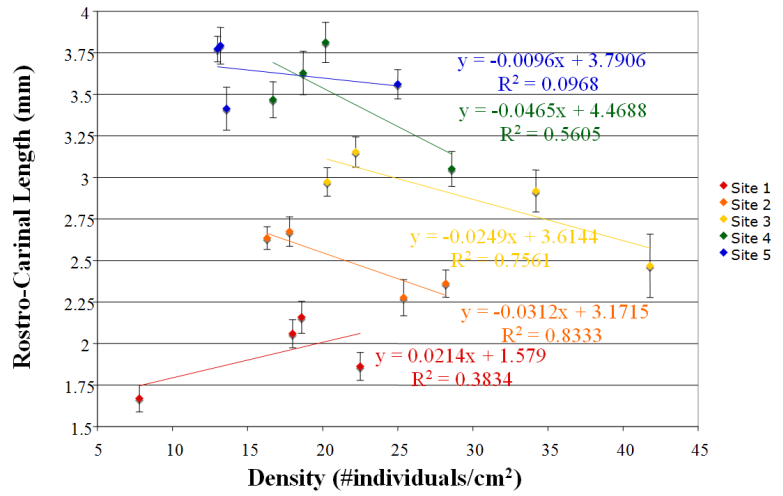

Figure 6: Linear regression applied to average rostrocarinal lengths $(\mathrm{mm})$ of the common barnacle (Semibalanus balanoides) and density (\# individuals $/ \mathrm{cm}^{2}$ ) of each site sampled over the four days. Comparisons between rostrocarinal length and density are isolated to similarly situated sites. Values are means \pm 1 s.e.m. of fifty rostro-carinal length measurements. Equation of linear regression lines and coefficient of determination values $\left(R^{2}\right)$ are expressed on graph for each of the five site isolations.

$\mathrm{R}^{2}=0.8333$ for the Site 2 grouping, $\mathrm{R}^{2}=0.7561$ for the Site 3 grouping, the Site 4 grouping $\mathrm{R}^{2}$ value is 0.5605 , and $\mathrm{R}^{2}=0.0968$ for the Site 5 grouping (Figure 6). Through additional analysis of the $\mathrm{R}^{2}$ value, and determination of the $R$ value, again by taking the square root of the $R^{2}$ value, it is found that the correlation between rostro-carinal length and density varies with each site type. Density and rostro-carinal length is most strongly correlated for the Site 2 grouping, reflected by $\mathrm{R}=0.9129$, and most weakly correlated for the Site 5 grouping, as demonstrated by $\mathrm{R}=0.3111$. The correlations of these factors for the groupings of sites 1, 3, and 4 are all fairly strong, indicated by the respective $\mathrm{R}$ values of $0.6192,0.8695$, and 0.7487 .

Also, the elevation below shore $(\mathrm{m})$ was measured for each site and graphed with the duration of aerial exposure at each site (Figure 7). Through application of a linear regression model, the equation of the line for this data is $y=-$ $2.1065 x+11.807$ (Figure 7). Again, the negative slope of this equation reflects the negative relationship between elevation and time spent by each site exposed to air during one tidal cycle; the larger the elevation below shoreline of the site location the shorter the duration of aerial exposure experienced by the site. Also, with an $\mathrm{R}^{2}$ value of 0.9649 for this graphed data, $96.49 \%$ of the variation in duration of aerial exposure data is accounted for by the variation in elevation data (Figure 7). Further, since the twenty sites represent a sample of all possible sites in the Indian Point sampling area, again the R-value was calculated by taking the square-root of the $R^{2}$ value. As a result, $R=0.9823$ indicates that the elevation below shoreline and time of aerial exposure of each site is very highly correlated, and is 


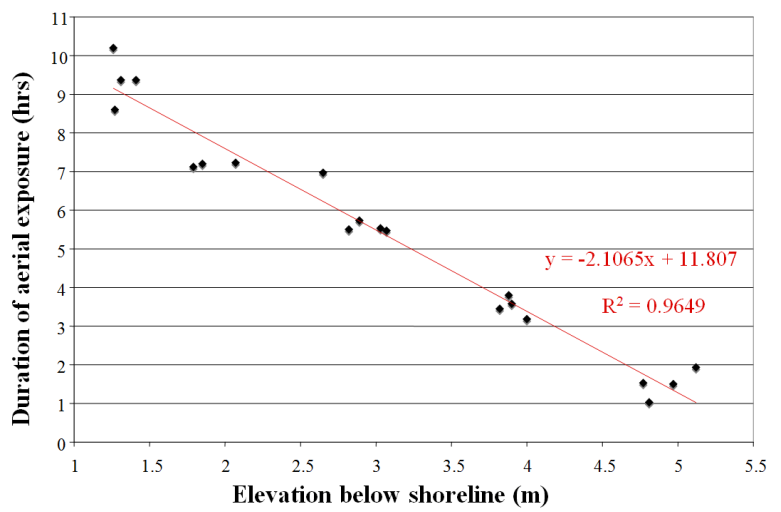

Figure 7: Linear regression applied to compare elevation (m) of each sampling site and time (hrs) the common barnacles (Semibalanus balanoides) spends exposed to air at each respective site. Elevations are measured relative to the elevation at the shoreline using a theodolite. Duration of aerial exposure (hrs) recorded over one tidal cycle (one high tide and one low tide) of the semidiurnal tide. Equation of linear regression line and coefficient of determination value $\left(\mathbf{R}^{2}\right)$ expressed on graph.

negatively correlated as reflected by the negative slope of the linear regression line.

\section{DiscuSSION}

The predictions were supported by the results; the size of $S$. balanoides is constrained by increased durations of aerial exposure. In the field, it was found that individuals inhabiting rocks located higher in the intertidal zone, and at elevations closer to the elevation at the shore $(0 \mathrm{~m})$, were out of water for longer periods of time. These individuals measured, on average, a smaller rostro-carinal length than $S$. balanoides found at the lower regions of the intertidal zone, where elevations were further below the shore elevation and exposure time was decreased.

The five sample sites enabled a good examination of how duration of exposure influences $S$. balanoides size. However, with a sixth site added, one where $S$. balanoides remained submerged at the lowest level reached by low tide during the time of greatest tide height, a more complete examination would have been possible. This sixth site would have provided individuals under conditions opposite to the barnacles sampled near the highest level of high tide, and exposed for almost one entire tidal cycle. Complete submersion provides the optimum conditions for growth, while prolonged exposure limits growth. ${ }^{10}$ The original methodology for this study included a sixth site, but due to time constraints and inaccessibility to fully submerged $S$. balanoides inhabited rocks, the planned sixth site was not sampled and the methodology was altered.

Through application of a linear regression model to the results, it was determined that body size and aerial exposure time are related linearly and are highly negatively correlated, as demonstrated by the $\mathrm{R}$ value of 0.9205 and negative slope of the line. Support for these results comes from a number of different sources. $S$. balanoides individuals that are submerged for longer periods have more access to food, and, therefore, grow to larger sizes, while individuals exposed for longer periods of time, have less ability to feed, do not grow as much, and, are, therefore, smaller on average. ${ }^{3,6,8,10}$ With this support, it can be appreciated how access to food is a determining factor for growth in $S$. balanoides.

However, with an $\mathrm{R}^{2}$ value of 0.8474 , the ability to reliably forecast average size of $S$. balanoides from known durations of aerial exposure is limited, with the assumption that an $\mathrm{R}^{2}$ value of 1.00 allows for accurate forecasting between related variables. It is possible that other factors were at play during sampling at Indian Point, including density, time of cyprid settlement, extreme heat, algal growth and physical relocation of $S$. balanoides-inhabited rocks. The influence of these factors is discussed below.

First, density of $S$. balanoides inhabiting the rock substrate has been documented as a variable that affects growth in this intertidal marine species. As density increases, individuals experience compromised food access. ${ }^{8,}$, 11 However, the extent to which density interferes with the relationship between rostro-carinal length and duration of aerial exposure is uncertain. As demonstrated by Figure 6, a negative relationship between density and rostro-carinal length was identified for groupings of sites 2, 3, 4, and 5 . Conversely, the grouping of sites 1 displayed a positive relationship between density and rostro-carinal length (Figure 6). The variability in strength and type of correlation presented by the different site groupings makes it difficult to formulate an overall conclusion of how density influences rostro-carinal length. Aside from this, the overlap between data points for Site 5 and Site 4 groupings, Site 4 and Site 3 groupings, and Site 3 and Site 2 groupings suggests that density influences the relationship between rostro-carinal length and duration of aerial exposure (Figure 6). As displayed in Figure 6, the overlaps that occur between site groupings and lower than expected measured average rostrocarinal lengths, can, generally, in each case, be explained by an increased density at that site.

In addition, neighbouring $S$. balanoides may disrupt each other's feeding when there is contact between adjacent cirral nets (fleshy feeding apparatus that barnacles eject from the shell to catch food particles suspended in the passing water). ${ }^{8}$ The frequency of this event is enhanced by population density, and, when increased, results in smaller than expected barnacles.

Next, the time of cyprid settlement has a direct impact on the rostro-carinal length of the measured $S$. balanoides. ${ }^{12,}$ 13, 14 The commencement of $S$. balanoides settlement on rocks normally occurs between the end of March and early April. ${ }^{12,}{ }^{13}$ Synchronized with the diatom boom, this is a successful time of cyprid growth into a young barnacle due to the maximal food availability. ${ }^{6}$ Settlement continues 
throughout the summer, usually ending in late July. ${ }^{12,}{ }^{13}$ Therefore individuals that were part of the first settler grouping would be larger than those that settled later in the season; earlier settlers would have more time to feed and grow before time of sampling in August. The short timeframe of sampling for this study (only four days of fieldwork) made accounting for this variable extremely difficult. Only when sites are observed from the beginning to the end of the settlement season may a more accurate measurement of age and feeding behaviour be considered. ${ }^{11}$ Therefore, the difference in size of $S$. balanoides between sites may be skewed by the natural difference in size between early and late settlers.

However, since the field area at high tide demonstrates consistent environmental conditions that affect settlement, with all sampled $S$. balanoides submerged, it was assumed that the early and late settlers were well mixed amongst all sites sampled, and that the influence of time of settlement on skewing the results was minimal. In future studies, consideration for the change in the tide height throughout the year, as well as its affects on time of settlement and implications to population dynamics may provide more encompassing results having accounted for this confounding variable. This is most crucial in the event that each, or any of sites 1 are not submerged at high tide, whereby further depleting S. balanoides food accessibility.

Another possible confounding variable that may have affected the relationship between body size and duration of aerial exposure is extreme heat. Although the cause is not yet completely understood, extreme heat retards growth. ${ }^{6,12,13}$ Since all sites were exposed to direct summer sunlight (on sunny days) when out of water, some barnacles, especially those exposed during the hottest times of the day, may be smaller because of the effects of the heat and not only because of the inability to feed when out of water.

An additional factor that has been found to limit $S$. balanoides growth is the presence of algae growing on the rocks. ${ }^{7}$ Since no algal growth was observed on the rocks sampled in this study, the effects of algae are not an applicable factor.

A final event that may have influenced the results, but which has not been considered by other studies, is the case of barnacle-inhabited rocks being picked up and physically moved by people walking along the intertidal zone. This is considered a potentially good explanation for the difference in the first two data points of Figure 4 between Days 2 and 4, and Days 1 and 3. For Days 2 and 4 the results are in line with what was expected and show support for the predictions (Figure 4). Since the second data points (from left to right on Figure 4) for Days 1 and 3 show $S$. balanoides inhabitants with larger average rostro-carinal lengths, it is assumed that these points represent rock substrates that were moved closer to shore. However, only with constant monitoring of the sampling area at Indian Point would the significance of this factor be accurately determined; therefore rock relocation as a factor is purely speculative.
While these factors have been considered, an alternative view is that the effects of these other variables may not be significant and the variation in duration of aerial exposure may not account for all of the variation in size of $S$. balanoides; the $\mathrm{R}^{2}$ value may not be equal to one. Therefore, further experimentation in the field will allow for a better understanding of whether other variables are responsible, or whether an $\mathrm{R}^{2}$ value less than one is an accurate relationship between these variables. Important elements to consider that may be applied to the methodology used in further experimentation include better characterization of aerial exposure and changes in environmental temperature at each site, improved attention paid to physical relocation of sites and the degree of algal influence at each site, and a more long-term sampling of the area so as to observe time of cyprid settlement and the ongoing effects of temperature on growth in S. balanoides.

A fuller understanding of the likelihood of $S$. balanoides found at different sites surviving into the following season and later can be achieved by comparing the results of this field-based study with the findings obtained by other studies. The ability of a barnacle to survive from year to year and endure the harsh winter conditions is highly dependant on the barnacle's size. ${ }^{3}$ Larger sized $S$. balanoides at the end of the summer season have an advantage over smaller ones ${ }^{1}$; larger individuals have a smaller surface-area-to-volume ratio and are therefore better able to store heat and retain moisture. ${ }^{1,3}$ Therefore, it is optimal for $S$. balanoides to settle early in the season and live further down the intertidal zone in order to reach an optimal size that will allow for winter survival. As such, it is expected that the Indian Point $S$. balanoides sampled closer to shore, with the smallest measured rostrocarinal lengths, will not survive winter. However, since no threshold size for $S$. balanoides winter survival has been documented, it is difficult to be certain which barnacles sampled in this study will remain at Indian Point during summer 2010.

Taking into account the identified constraints, the results of this study provide valuable insight into how settlement location plays a significant role in determining the degree to which changes in environmental conditions affect the physiology and subsequent survival of $S$. balanoides. These results are in line with the understanding that immersion is a significant factor that determines the survival of sessile marine animals that are exposed to the unfavorable pressures in the intertidal zone. ${ }^{4}$ Field research, such as this study, is useful in providing information about conditions in which species exist. This information allows lab-based studies to reproduce natural conditions and to more accurately draw insights into how species respond to a change in environmental conditions. Knowledge of this relationship is especially important for biologists attempting to predict the effects of climate change on the diversity and abundance of Earth's species. 


\section{REFERENCES}

1. Foster BA. 1971. Dessication as a factor in the intertidal zonation of barnacles. Mar Biol. 8: 12-29.

2. Murphy D. 1983. Freezing resistance in intertidal invertebrates. Ann. Rev. Physiol. 45: 289-299.

3. Foster BA. 1971. On the determinants of the upper limit of intertidal distribution of barnacles (crustacea: cirripedia). $J$ Anim Ecol. 40: 33-48.

4. Wethey DS. 1984. Sun and shade mediate competition in the barnacles Chthamalus and Semibalanus: a field experiment. Biol Bull. 167: 176-185.

5. Bertness MD, Leonard GH, Levine JM, Bruno JF. 1999. Climate-driven interactions among rocky intertidal organisms caught between a rock and a hot place. Oecologia. 120: 446-450.

6. Barnes H, Barnes M. 1959. A comparison of the annual growth patterns of Balanus balanoides (L.) with particular reference to the effect of food and temperature. Oikos. 10: 118.
7. Barnes H. 1955. The growth rate of Balanus balanoides (L.). Oikos. 6: 109-113.

8. Crisp D. 1960. Factors influencing growth-rate in Balanus balanoides. J. Anim. Ecol. 29: 95-116.

9. Park M, Moore H. 1935. The biology of Balanus balanoides. II Algal infection of the shell. J. Mar. Biol. Ass. UK. 20: 49-56.

10. Barnes H, Powell H. 1953. The growth rate of Balanus balanoides (L.) and $B$. crenatus Brug. under varying conditions of submersion. J. Mar. Biol. Ass. UK. 32: 107128.

11. Connell J. 1961. Effects of competition, predation by Thais lapillus, and other factors on natural populations of the barnacle Balanus balanoides. Ecol. Mono. 31: 61-104.

12. Moore H. 1934. The biology of Balanus balanoides: I. Growth rate and its relation to size, season and tidal level. $J$. Mar. Biol. Assoc. UK. 19: 851-868.

13. Moore H. 1935. The biology of Balanus balanoides. III. The soft parts. J. Mar. Biol. Ass. UK. 20: 263-277.

14. Raimondi P. 1988. Settlement cues and determination of the vertical limit of an intertidal barnacle. Ecology. 69: 400407. 